\title{
Mn-Promoted Growth and Photoluminescence of Molybdenum Disulphide Monolayer
}

\author{
Shengzhong Jin, Shichao Zhao *, Jiaxin Weng and Yanfei Lv \\ College of Materials \& Environmental Engineering, Hangzhou Dianzi University, Hangzhou 310018, China; \\ wk_jsz@163.com (S.J.); weng_jiaxin@126.com (J.W.); lvyanfei@hdu.edu.cn (Y.L.) \\ * Correspondence: zhaoshichao@hdu.edu.cn; Tel.: +86-571-8771-3537 \\ Academic Editor: Mingheng Li \\ Received: 4 May 2017; Accepted: 6 June 2017; Published: 8 June 2017
}

\begin{abstract}
Molybdenum disulphide $\left(\mathrm{MoS}_{2}\right)$ monolayer is a two-dimensional semiconductor material with potential applications in nano electronic devices. However, it is still a challenge to reproducibly synthesize single layer $\mathrm{MoS}_{2}$ in high quality. Herein, we report the growth of monolayer of $\mathrm{MoS}_{2}$ on the $\mathrm{SiO}_{2} / \mathrm{Si}$ substrate with manganese heterogeneous nucleation. It was shown that the $\mathrm{Mn}$ promotes the growth of monolayer $\mathrm{MoS}_{2}$ via heterogeneous nucleation. The growth temperature range expanded two-fold, the nucleation density increased as well. The monolayer prepared in the presence of Mn exhibits a unique red emission peak at $732 \mathrm{~nm}$ at room temperature compared to the sample in the absence of Mn.
\end{abstract}

Keywords: molybdenum disulphide; heterogeneous nucleation; growth; photoluminescence

\section{Introduction}

Molybdenum disulphide $\left(\mathrm{MoS}_{2}\right)$ monolayer is a direct band gap semiconductor with unique electronic and optical properties. It has many potential applications in electronic, optoelectronic, bionanoelectronic devices, and hydrogen generation [1-6]. Due to these promising applications, $\mathrm{MoS}_{2}$ monolayer crystalline has been successfully prepared by vapor deposition on the insulating substrates [7-11]. However, reproducible control of $\mathrm{MoS}_{2}$ growth using the aforementioned methods is still challenging. For example, the atomic ratio of Mo:S and nucleation are out of control. Lee et al. and Ling et al. reported that the nucleation is sensitive to the seeding promoters $[12,13]$. As we know, $\mathrm{MoS}_{2}$ solid power used as a precursor provides a stoichiometric evaporation of $\mathrm{MoS}_{2}$. Wu et al. are among the first to report vapor deposition (VD) synthesis of $\mathrm{MoS}_{2}$ monolayer using $\mathrm{MoS}_{2}$ as a precursor [9]. The lateral size of $\mathrm{MoS}_{2}$ single crystal is up to $25 \mu \mathrm{m}$. Many studies have reported that the underlying metal substrates show great influence on VD-grown $\mathrm{MoS}_{2}$, for example, $\mathrm{Cu}, \mathrm{Ni}, \mathrm{Al}$, and $\mathrm{Ag}[14,15]$. However, few reports are found on the preparation of $\mathrm{MoS}_{2}$ monolayer with manganese $(\mathrm{Mn})$ as seeding promoter [16]. Herein, we prepared the monolayer of $\mathrm{MoS}_{2}$ on the $\mathrm{SiO}_{2} / \mathrm{Si}$ substrate pre-coated with a layer of $\mathrm{Mn}$. Monolayer growth was strongly sensitive to the growth temperature and Mn substrate. In addition, the photoluminescence (PL) of the monolayer was greatly influenced by the existence of $\mathrm{Mn}$. Our findings provide a novel technique to synthesize monolayer $\mathrm{MoS}_{2}$ in high quality with improved optical properties.

\section{Materials and Methods}

$\mathrm{MoS}_{2}$ was prepared by a previously reported vapor deposition (VD) method using a silicon wafer with $300 \mathrm{~nm}$ of oxide layer $\left(\mathrm{SiO}_{2} / \mathrm{Si}\right)$ as the substrate [9], as shown in Figure 1a. $\mathrm{MoS}_{2}$ powder (Aladdin, Shanghai, China, 99.5\% purity) was used as the precursor. Before use, the precursor $(0.5 \mathrm{~g})$ was loaded into a small quartz glass boat $(70 \mathrm{~mm}$ length) and was put in the center of the tube furnace. 
Before growth, the precursor was flushed under $\mathrm{Ar} / \mathrm{H}_{2}\left(70 \mathrm{sccm}, \mathrm{H}_{2} 5 \%\right.$, total pressure of 75 Torr. sccm: standard cubic centimeter per minute) for $10 \mathrm{~min}$ at room temperature to remove air and water absorbed on the precursor. The substrate was put downstream close to the furnace wall.

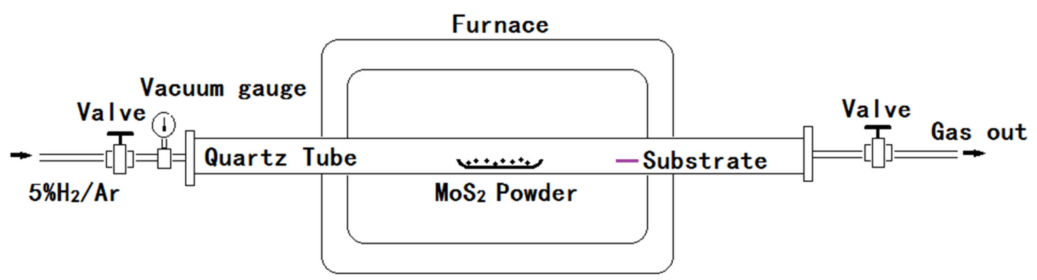

(a)

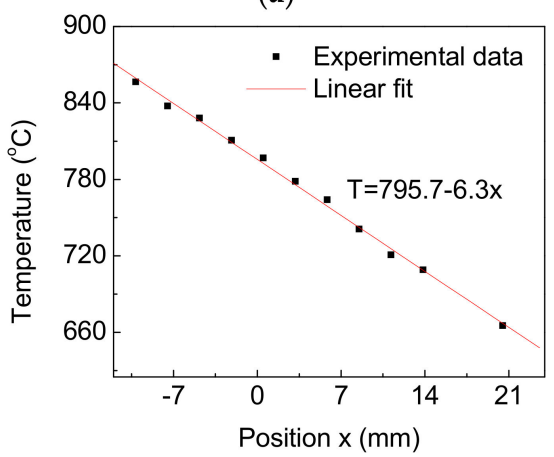

(b)

Figure 1. (a) Schematic of the $\mathrm{MoS}_{2}$ growth setup; (b) Plot of temperature vs. position near the $\mathrm{MoS}_{2}$ growth area, and the linear fit of the data. The origin of the $x$-coordinate is chosen in the center of the sample. The positive direction of $x$-axis is along the gas flow direction.

For the $\mathrm{MoS}_{2}$ growth, the precursor was heated to $1000{ }^{\circ} \mathrm{C}$ from room temperature in $30 \mathrm{~min}$ under vacuum ( $75 \mathrm{Torr}, \mathrm{Ar} / \mathrm{H}_{2} 70 \mathrm{sccm}$ ) and kept at $1000{ }^{\circ} \mathrm{C}$ for $10 \mathrm{~min}$. Then total pressure was increased to atmospheric pressure before that the carrier gas flow was turned off. After that, the precursor was kept at $1000{ }^{\circ} \mathrm{C}$ for $2 \mathrm{~h}$ for the $\mathrm{MoS}_{2}$ growth. Afterward, the furnace was turned off and cooled from $1000{ }^{\circ} \mathrm{C}$ to room temperature. The vapor of the precursor was introduced to the growth area by $\mathrm{Ar} / \mathrm{H}_{2}$ gas flow and deposited onto the substrate. The temperature of the area ranged from 710 to $850^{\circ} \mathrm{C}$.

For the Mn substrate preparation, Mn metal powder (Aladdin, $99.9 \%$ purity) was used as the precursor. The precursor $(2.0 \mathrm{~g})$ was loaded onto a small quartz glass boat $(70 \mathrm{~mm}$ length) and was put in the center of the tube furnace. The silicon wafer with oxide layer $\left(\mathrm{SiO}_{2} / \mathrm{Si}\right)$ used as the substrate was put downstream close to the furnace wall. Mn metal power was heated to $900{ }^{\circ} \mathrm{C}$ from room temperature in $30 \mathrm{~min}$ and kept at $900{ }^{\circ} \mathrm{C}$ for $90 \mathrm{~min}$ under vacuum (75 Torr, $\mathrm{Ar} / \mathrm{H}_{2} 70 \mathrm{sccm}$ ). $\mathrm{Mn}$ metal was evaporated and deposited onto the $\mathrm{SiO}_{2} / \mathrm{Si}$ substrate.

The temperature of the $\mathrm{MoS}_{2}$ growth area was obtained indirectly. First, we ran a blank test and obtained the temperature distribution inside the furnace, and plotted the temperature distribution curve in respect to the heat position as a reference. For the blank test, the furnace center temperature was kept at $1000{ }^{\circ} \mathrm{C}$. Then we confirmed the position where the sample had been loaded and checked with the temperature distribution curve in that position. In this way, we obtained the accurate growth temperature of the $\mathrm{MoS}_{2}$ and the uncertainty of the measurement is mainly from the measurement of the position of the sample. As shown in Figure 1b, the growth temperature $(T)$ vs. position $(x)$ shows a linear function of $T=795.7-6.3 x$ in the temperature range $665-856^{\circ} \mathrm{C}$. The origin of the $x$-coordinate is chosen in the center of the sample. The positive direction of $X$-axis is along the gas flow direction. The absolute error of position was $\pm 1 \mathrm{~mm}$. Therefore, the absolute error of the growth temperature is ca. $\pm 6{ }^{\circ} \mathrm{C}$. 
Optical microscope imaging of the sample was conducted with a Jiangnan MV3000 digital microscope (Nanjing jiangnan Novel Optics Co., Ltd., Nanjing, China). Tapping mode atomic force microscopy was performed on an Agilent 5500 (Palo Alto, CA, USA) in air. Raman spectrum and photoluminescence were acquired on a Renishaw inVia micro-Raman spectroscope (Renishaw, London, UK) with a $532 \mathrm{~nm}$ solid state laser at room temperature.

\section{Results and Discussion}

To investigate the growth behavior of $\mathrm{MoS}_{2}$ with or without Mn seeding promoter, we used two methods to prepare $\mathrm{MoS}_{2}$. The difference lied in the substrate that treated with or without Mn vapor. In the first method, the $\mathrm{MoS}_{2}$ was grown on the bare $\mathrm{SiO}_{2} / \mathrm{Si}$ substrate. In the second method, $\mathrm{Mn}$ metal was evaporated at $900{ }^{\circ} \mathrm{C}$ for $90 \mathrm{~min}$ under vacuum (75 Torr, $\mathrm{Ar} / \mathrm{H}_{2} 70 \mathrm{sccm}$ ) onto the $\mathrm{SiO}_{2} / \mathrm{Si}$ substrate $\left(\mathrm{Mn} / \mathrm{SiO}_{2} / \mathrm{Si}\right)$ before the $\mathrm{MoS}_{2}$ growth. Optical images of the $\mathrm{MoS}_{2}$ film were shown inFigures 2 and $3 . \mathrm{MoS}_{2}$ monolayer domains were only found on the higher temperature region of the substrate. The growth temperature ranged from ca. 780 to $725^{\circ} \mathrm{C}$ for the $\mathrm{SiO}_{2} / \mathrm{Si}$ substrate, while it was about $855-730^{\circ} \mathrm{C}$ for the $\mathrm{Mn} / \mathrm{SiO}_{2} / \mathrm{Si}$ substrate. The range of growth temperature was about two times wider for Mn catalyzed $\mathrm{MoS}_{2}$ growth, compared to that without the existence of $\mathrm{Mn}$. It also can be observed that the domain size increases with the increase of the temperature in both samples. The largest size (ca. $140 \mu \mathrm{m}$ ) was obtained at about $770{ }^{\circ} \mathrm{C}$ on the $\mathrm{SiO}_{2} / \mathrm{Si}$ substrate.

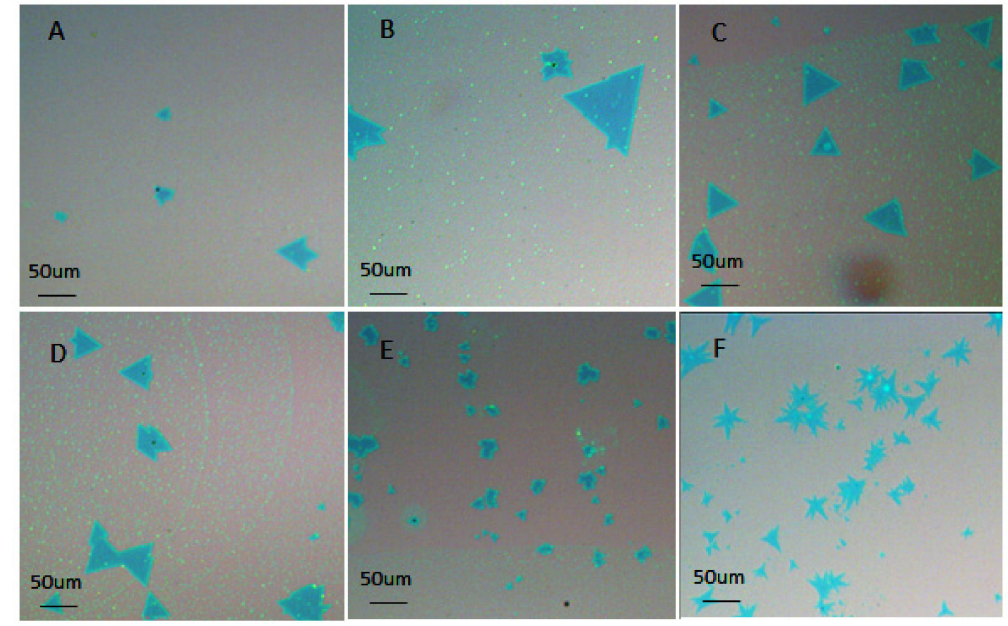

Figure 2. The optical images of the $\mathrm{MoS}_{2}$ flakes grown on $\mathrm{SiO}_{2} / \mathrm{Si}$ substrate with different temperatures: (A) $780{ }^{\circ} \mathrm{C},\left(\right.$ B) $770{ }^{\circ} \mathrm{C},(\mathbf{C}) 760{ }^{\circ} \mathrm{C}$, (D) $750{ }^{\circ} \mathrm{C}$, (E) $736{ }^{\circ} \mathrm{C}$, and (F) $725^{\circ} \mathrm{C}$.

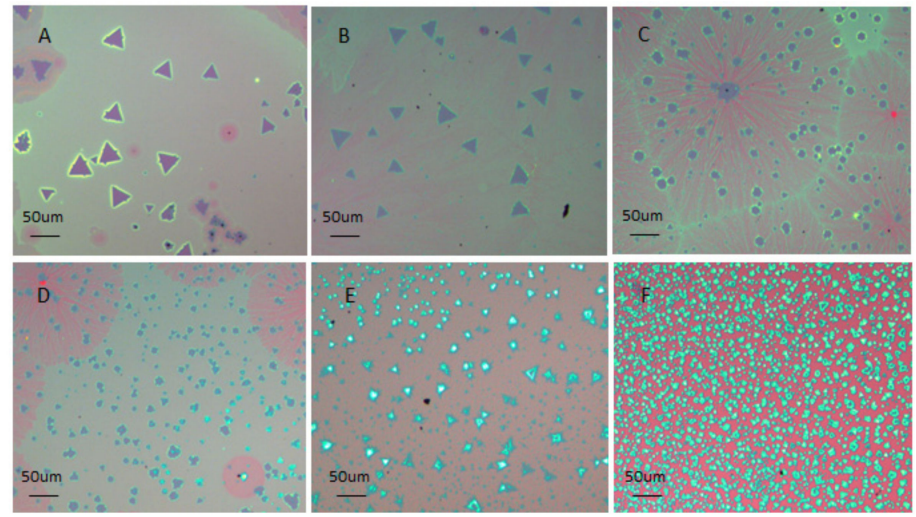

Figure 3. The optical images of the $\mathrm{MoS}_{2}$ flakes grown on $\mathrm{Mn} / \mathrm{SiO}_{2} / \mathrm{Si}$ substrate with different temperatures: (A) $855^{\circ} \mathrm{C},(\mathbf{B}) 837^{\circ} \mathrm{C},(\mathbf{C}) 828^{\circ} \mathrm{C}$, (D) $812^{\circ} \mathrm{C},\left(\right.$ E) $749^{\circ} \mathrm{C}$, and (F) $730^{\circ} \mathrm{C}$. 
Meanwhile, the shape becomes a regular triangle at elevated temperature Figure 2A-D and Figure $3 \mathrm{~A}, \mathrm{~B}$, indicating that these domains are of high crystallinity. In addition, the optical images of these domains in Figure 2A-D and Figure 3A,B show a uniform color contrast on the substrate, suggesting high thickness uniformity of the $\mathrm{MoS}_{2}$ domain.

The optical contrast of the particles grown at lower temperature (Figure $3 \mathrm{E}, \mathrm{F}$ ) indicates that the $\mathrm{MoS}_{2}$ multi-layers are formed. The density of the domain or particles on the $\mathrm{Mn} / \mathrm{SiO}_{2} / \mathrm{Si}$ substrate is greater than that on the $\mathrm{SiO}_{2} / \mathrm{Si}$ substrate. These results are in agreement with our hypothesis that $\mathrm{Mn}$ promotes heterogeneous nucleation of $\mathrm{MoS}_{2}$ during the growth.

Typical AFM image of the $\mathrm{MoS}_{2}$ domain grown on the $\mathrm{SiO}_{2} / \mathrm{Si}$ at $760{ }^{\circ} \mathrm{C}$ is shown in Figure 4 . The thickness of the $\mathrm{MoS}_{2}$ domain $0.62 \pm 0.1 \mathrm{~nm}$ (Figure 3), is consistent with the reported value of monolayer film $[17,18]$, indicating that the $\mathrm{MoS}_{2}$ domain is monolayer.

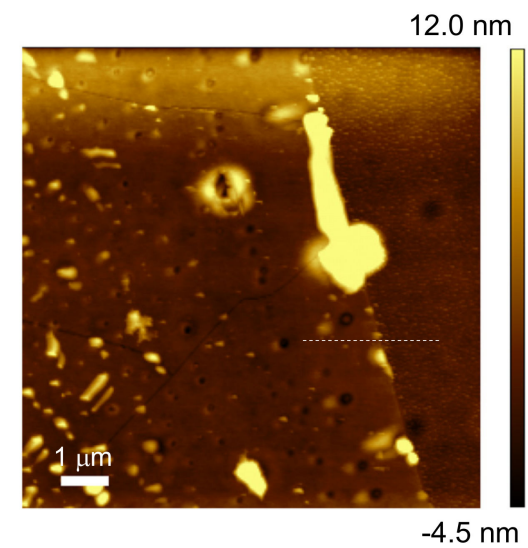

(a)

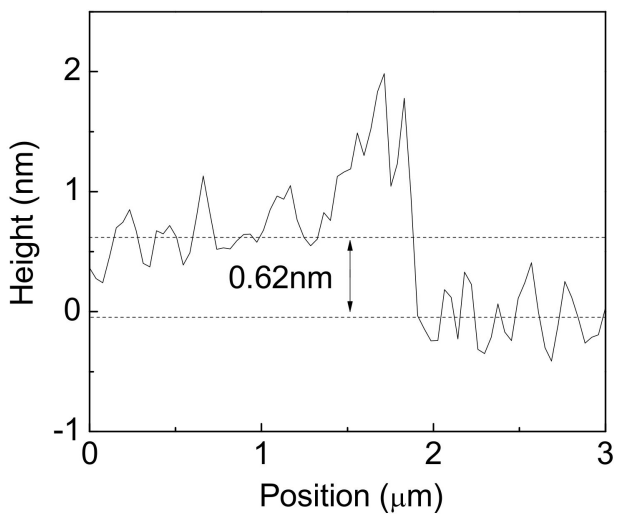

(b)

Figure 4. AFM image and cross section of $\mathrm{MoS}_{2}$ grown on a $\mathrm{SiO}_{2} / \mathrm{Si}$ substrate. The line indicates the location where the cross section was determined. Scale bar in the AFM image represents $1 \mu \mathrm{m}$. (a) AFM; (b) Cross section of the marked area in (a).

Figure 5 displays the typical Raman spectra of monolayer $\mathrm{MoS}_{2}$ triangular domain corresponded to the images in Figures $2 \mathrm{C}$ and $3 \mathrm{~B}$, respectively. The frequency difference between the $\mathrm{E}_{2 \mathrm{~g}}$ and $\mathrm{A}_{1 \mathrm{~g}}$ modes of $\mathrm{MoS}_{2}$ is conveniently used for rapid and accurate determination of the thickness of $\mathrm{MoS}_{2}$. The frequency difference of the monolayer $\mathrm{MoS}_{2}$ is ca. $20 \mathrm{~cm}^{-1}[13,19]$. The $\mathrm{E}_{2 \mathrm{~g}}$ and $\mathrm{A}_{1 \mathrm{~g}}$ modes of $\mathrm{MoS}_{2}$ are located at 384.7 and $404.6 \mathrm{~cm}^{-1}$ for the sample grown on bare $\mathrm{SiO}_{2} / \mathrm{Si}$ substrate, with a frequency difference of $19.9 \mathrm{~cm}^{-1}$ between these two modes, In comparison, $\mathrm{MoS}_{2}$ grown in the presence of Mn demonstrates a frequency difference of $21.7 \mathrm{~cm}^{-1}$, locating at a Raman shift of $382.4 \mathrm{~cm}^{-1}$ and $404.1 \mathrm{~cm}^{-1}$, respectively. The frequency difference value in both samples consisted with the value of monolayer $\mathrm{MoS}_{2}$, confirming the successful preparation of $\mathrm{MoS}_{2}$ monolayer [13,19]. We observed that the peak positions of the sample prepared in the presence of Mn catalyst are red shifted compared to those grown on the bare $\mathrm{SiO}_{2} / \mathrm{Si}$ substrate. Besides the red shift, a shoulder right to the defect-related 2LA (M) Raman band was also observed [19]. It is possible that the red shift and the shoulder are caused by Mn seeding promoter inducing strain defects during the growth of $\mathrm{MoS}_{2}$, such as the heterogeneous nucleating.

In contrast to multi-layer or bulk $\mathrm{MoS}_{2}$, the optical bandgap of monolayer $\mathrm{MoS}_{2}$ is direct. Under photon excitation, strong PL emission will be found in monolayer $\mathrm{MoS}_{2}$. Figure 6 shows the typical photoluminescence spectra (PL) of the monolayer $\mathrm{MoS}_{2}$ triangular domain corresponded to the images in panel C of Figure 2 and panel B of Figure 3, respectively. The excitation wavelength was $532 \mathrm{~nm}$. The PL peak at ca. $680 \mathrm{~nm}(1.82 \mathrm{eV})$ and $632 \mathrm{~nm}(1.96 \mathrm{eV})$ are attributed to the $\mathrm{A} 1$ and B1 direct excitonic transition emission of $\mathrm{MoS}_{2}$ monolayer $[11,17,20]$. The PL peaks were fitted with Gaussian curves. The full width at half maximum (FWHM) of the peak at ca. $680 \mathrm{~nm}$ is $52.3 \pm 0.3 \mathrm{~nm}$ for the sample grown 
on $\mathrm{SiO}_{2} / \mathrm{Si}$ substrate, and $16.5 \pm 0.2 \mathrm{~nm}$ for the sample grown on $\mathrm{Mn} / \mathrm{SiO}_{2} / \mathrm{Si}$ substrate. The strong PL intensity and reduced FWHM at $680 \mathrm{~nm}$ indicate that the high quality of the monolayer of $\mathrm{MoS}_{2}$ was successfully prepared on the $\mathrm{Mn} / \mathrm{SiO}_{2} / \mathrm{Si}$ substrate. We interpret the strong PL peak intensity and reduced FWHM at $680 \mathrm{~nm}$ are concerned with the heterogeneous nucleation of $\mathrm{MoS}_{2}$. Ling et al. recently studied the $\mathrm{MoS}_{2}$ monolayer growth using seeding promoter [13]. They found that the seeding promoter played a major role in the nucleation and even the domain quality of the $\mathrm{MoS}_{2}$.

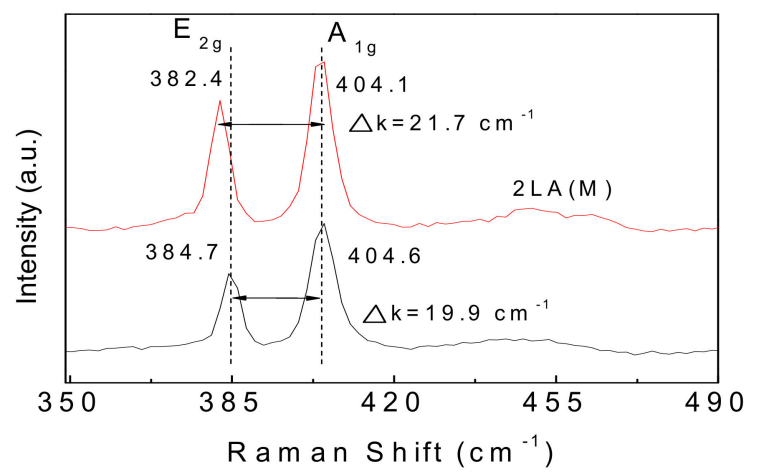

Figure 5. Typical Raman spectra of $\mathrm{MoS}_{2}$ samples grown on $\mathrm{Mn} / \mathrm{SiO}_{2} / \mathrm{Si}$ substrate (red line) and $\mathrm{SiO}_{2} / \mathrm{Si}$ substrate (black line), respectively.

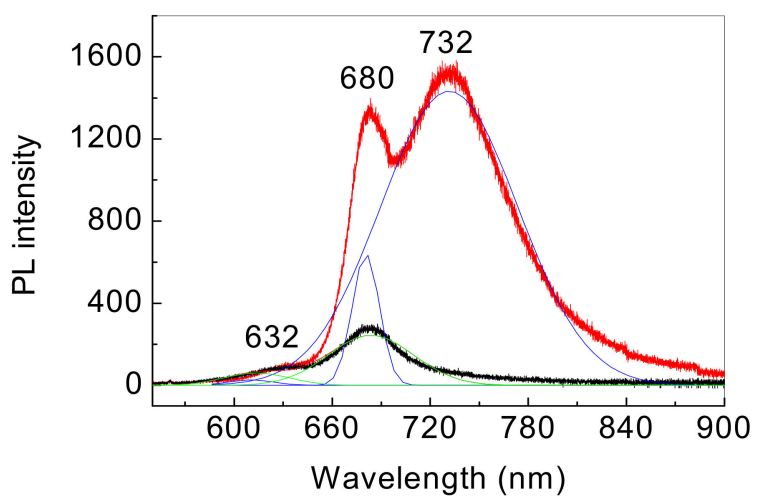

Figure 6. Typical PL spectra of $\mathrm{MoS}_{2}$ samples grown on $\mathrm{Mn} / \mathrm{SiO}_{2} / \mathrm{Si}$ substrate (red line) and $\mathrm{SiO}_{2} / \mathrm{Si}$ substrate (black line), respectively. Green lines are the Gaussian fit to the black line, and blue lines are the Gaussian fit to the red line.

Besides the peak at $680 \mathrm{~nm}$, an unexpected stronger and broader low energy peak centered at $732 \mathrm{~nm}(1.69 \mathrm{eV})$ with a FWHM of $70.0 \mathrm{~nm}$ was observed at room temperature in the sample grown on the $\mathrm{Mn} / \mathrm{SiO}_{2} / \mathrm{Si}$ substrate. This peak may be produced by the recombination of defect-bound excitons. Tongay et al. observed a defect-induced bound exciton peak at ca. $1.78 \mathrm{eV}$, and the peak disappeared as the temperature is higher than $250 \mathrm{~K}$ [21]. Here it is possible that the strain-induced defects were formed during the heterogeneous nucleation, resulting in emission at $732 \mathrm{~nm}$ at room temperature. Detailed studies of the peak will be reported in future work.

\section{Conclusions}

In summary, we have successfully prepared high quality monolayer $\mathrm{MoS}_{2}$ with regular triangular morphology and high thickness uniformity by $\mathrm{VD}$ method on $\mathrm{SiO}_{2} / \mathrm{Si}$ substrate with/without a coating layer of $\mathrm{Mn}$ as seeding promoters. The growth of $\mathrm{MoS}_{2}$ is highly sensitive to the temperature. The results reveal that the $\mathrm{MoS}_{2}$ growth is limited to a specific temperature range, and the range is expanded two-fold in the presence of Mn. In addition, we also found the nucleation density was 
increased on the substrate with Mn seeding promoter. Both the Raman and PL spectra revealed that the $\mathrm{MoS}_{2}$ domain grown at elevated temperature is monolayer. The PL spectra of the monolayer showed A1 excitation emission at $680 \mathrm{~nm}$, while a unique and strong emission at $732 \mathrm{~nm}$ was obtained for the monolayer $\mathrm{MoS}_{2}$ prepared in the presence of Mn.

Acknowledgments: This work was supported by Natural Science Foundation of Zhejiang Province, China Projects (LY16E020008), and Chinese NSF Projects (61106100).

Author Contributions: Shengzhong Jin designed and performed the experiments; Jiaxin Weng performed the experiments; Shichao Zhao and Yanfei Lv analyzed the data and wrote the paper.

Conflicts of Interest: The authors declare no conflict of interest.

\section{References}

1. Mak, K.F.; Lee, C.; Hone, J.; Shan, J.; Heinz, T.F. Atomically Thin $\mathrm{MoS}_{2}$ : A new direct-gap semiconductor. Phys. Rev. Lett. 2010, 105, 136805:1-136805:4. [CrossRef] [PubMed]

2. Jariwala, D.; Sangwan, V.K.; Lauhon, L.J.; Marks, T.J.; Hersam, M.C. Emerging device applications for semiconducting two-dimensional transition metal dichalcogenides. ACS Nano 2014, 8, 1102-1120. [CrossRef] [PubMed]

3. Hayamizu, Y.; So, C.R.; Dag, S.; Page, T.S.; Starkebaum, D.; Sarikaya, M. Bioelectronic interfaces by spontaneously organized peptides on 2D atomic single layer materials. Sci. Rep. 2016, 6, 33778:1-33778:9. [CrossRef] [PubMed]

4. Gan, X.R.; Zhao, H.M.; Quan, X. Two-dimensional $\mathrm{MoS}_{2}$ : A promising building block for biosensors. Biosens. Bioelectron. 2017, 89, 56-71. [CrossRef] [PubMed]

5. Mak, K.F.; Shan, J. Photonics and optoelectronics of 2D semiconductor transition metal dichalcogenides. Nat. Photonics 2016, 10, 216-226. [CrossRef]

6. Ma, S.; Xie, J.; Wen, J.Q.; He, K.L.; Li, X.; Liu, W.; Zhang, X.C. Constructing 2D layered hybrid CdS nanosheets $/ \mathrm{MoS}_{2}$ heterojunctions for enhanced visible-light photocatalytic $\mathrm{H}_{2}$ generation. Appl. Surf. Sci. 2017, 391, 580-591. [CrossRef]

7. Van Der Zande, A.M.; Huang, P.Y.; Chenet, D.A.; Berkelbach, T.C.; You, Y.M.; Lee, G.H.; Heinz, T.F.; Reichman, D.R.; Muller, D.A.; Hone, J.C. Grains and grain boundaries in highly crystalline monolayer molybdenum disulphide. Nat. Mater. 2013, 12, 554-561. [CrossRef] [PubMed]

8. Xie, Y.; Wang, Z.; Zhan, Y.J.; Zhang, P.; Wu, R.X.; Jiang, T.; Wu, S.W.; Wang, H.; Zhao, Y.; Nan, T.; et al. Controllable growth of monolayer $\mathrm{MoS}_{2}$ by chemical vapor deposition via close $\mathrm{MoO}_{2}$ precursor for electrical and optical applications. Nanotechnology 2017, 28, 084001:1-084001:11. [CrossRef] [PubMed]

9. Wu, S.F.; Huang, C.M.; Aivazian, G.; Ross, J.S.; Cobden, D.H.; Xu, X.D. Vapor-solid growth of high optical quality $\mathrm{MoS}_{2}$ monolayers with near-unity valley polarization. ACS Nano 2013, 7, 2768-2772. [CrossRef] [PubMed]

10. Luo, S.W.; Qi, X.; Ren, L.; Hao, G.L.; Fan, Y.P.; Liu, Y.D.; Han, W.J.; Zang, C.; Li, J.; Zhong, J.X. Photoresponse properties of large-area $\mathrm{MoS}_{2}$ atomic layer synthesized by vapor phase deposition. J. Appl. Phys. 2014, 116, 164304:1-164304:6. [CrossRef]

11. Kim, Y.; Bark, H.; Ryu, G.H.; Lee, Z.; Lee, C. Wafer-scale monolayer $\mathrm{MoS}_{2}$ grown by chemical vapor deposition using a reaction of $\mathrm{MoO}_{3}$ and $\mathrm{H}_{2}$ S. J. Phys. Condens. Matter 2016, 28, 184002:1-184002:6. [CrossRef] [PubMed]

12. Lee, Y.H.; Zhang, X.Q.; Zhang, W.J.; Chang, M.T.; Lin, C.T.; Chang, K.D.; Yu, Y.C.; Wang, J.T.W.; Chang, C.S.; Li, L.J.; et al. Synthesis of large-area $\mathrm{MoS}_{2}$ atomic layers with chemical vapor deposition. Adv. Mater. 2012, 24, 2320-2325. [CrossRef] [PubMed]

13. Ling, X.; Lee, Y.H.; Lin, Y.X.; Fang, W.J.; Yu, L.L.; Dresselhaus, M.S.; Kong, J. Role of the seeding promoter in $\mathrm{MoS}_{2}$ growth by chemical vapor deposition. Nano Lett. 2014, 14, 464-472. [CrossRef] [PubMed]

14. Loh, T.A.J.; Chua, D.H.C. Growth mechanism of pulsed laser fabricated few-layer $\mathrm{MoS}_{2}$ on metal substrates. ACS Appl. Mater. Interface 2014, 6, 15966-15971. [CrossRef] [PubMed]

15. Loh, T.A.J.; Tanemura, M.; Chua, D.H.C. Ultrathin $\mathrm{MoS}_{2}$ and $\mathrm{WS}_{2}$ layers on silver nano-tips as electron emitters. Appl. Phys. Lett. 2016, 109, 133102. [CrossRef] 
16. Zhang, K.H.; Feng, S.M.; Wang, J.J.; Azcatl, A.L.; Lu, N.; Addou, R.; Wang, N.; Zhou, C.J.; Lerach, J.; Bojan, V.; et al. Manganese doping of Monolayer $\mathrm{MoS}_{2}$ : The substrate is critical. Nano Lett. 2015, 15, 6586-6591. [CrossRef] [PubMed]

17. Wang, S.S.; Rong, Y.M.; Fan, Y.; Pacios, M.; Bhaskaran, H.; He, K.; Warner, J.H. Shape evolution of monolayer $\mathrm{MoS}_{2}$ crystals grown by chemical vapor deposition. Chem. Mater. 2014, 26, 6371-6379. [CrossRef]

18. Amani, M.; Chin, M.L.; Birdwell, A.G.; O’Regan, T.P.; Najmaei, S.; Liu, Z.; Ajayan, P.M.; Lou, J.; Dubey, M. Electrical performance of monolayer $\mathrm{MoS}_{2}$ field-effect transistors prepared by chemical vapor deposition. Appl. Phys. Lett. 2013, 102, 193107:1-193107:4. [CrossRef]

19. Mignuzzi, S.; Pollard, A.J.; Bonini, N.; Brennan, B.; Gilmore, I.S.; Pimenta, M.A.; Richards, D.; Roy, D. Effect of disorder on Raman scattering of single-layer $\mathrm{MoS}_{2}$. Phys. Rev. B 2015, 91, 195411:1-195411:7. [CrossRef]

20. Splendiani, A.; Sun, L.; Zhang, Y.B.; Li, T.S.; Kim, J.; Chim, C.Y.; Galli, G.; Wang, F. Emerging photoluminescence in monolayer $\mathrm{MoS}_{2}$. Nano Lett. 2010, 10, 1271-1275. [CrossRef] [PubMed]

21. Tongay, S.; Suh, J.; Ataca, C.; Fan, W.; Luce, A.; Kang, J.S.; Liu, J.; Ko, C.; Raghunathanan, R.; Zhou, J.; et al. Defects activated photoluminescence in two-dimensional semiconductors: Interplay between bound, charged, and free excitons. Sci. Rep. 2013, 3, 2657:1-2657:5. [CrossRef] [PubMed]

(C) 2017 by the authors. Licensee MDPI, Basel, Switzerland. This article is an open access article distributed under the terms and conditions of the Creative Commons Attribution (CC BY) license (http:/ / creativecommons.org/licenses/by/4.0/). 